\title{
A Educação Postural como conteúdo curricular da Educação Física no Ensino Fundamental II nas escolas da Cidade de Montenegro/RS
}

\author{
Cláudia Tarragô Candotti* \\ Jóice Elisa Rohr** \\ Matias Noll***
}

\begin{abstract}
Resumo: Este estudo teve como objetivo verificar se a Educação Postural está contemplada nos conteúdos das aulas de Educação Física das escolas de Ensino Fundamental de $5^{a}$ a 8 ${ }^{\text {a }}$ séries da cidade de Montenegro/RS. Todos os professores de Educação Física $(n=22)$ provenientes de todas as escolas Ensino Fundamental completo da cidade responderam um questionário auto-aplicável. Os resultados evidenciaram que a Educação Postural, na prática, é significativamente negligenciada pela maioria dos professores de Educação Física de $5^{\underline{a}}$ a $8^{\underline{a}}$ séries, embora os mesmos reconheçam a importância de ensinar e praticar questões sobre Educação Postural, bem como definem muito bem o conceito de postura adequada, o que sugere uma notável contradição entre o pensar e o fazer. Palavras-chave: Postura. Instituições de Ensino. Educação Física.
\end{abstract}

\section{INTRODUÇÃO}

Os problemas posturais e a ocorrência de dor lombar, além de estarem presentes em larga escala em adultos, manifestam-se também em grandes proporções na infância e na adolescência. Isto tem sido evidenciado em estudos realizados em vários continentes (RIBEIRO; GÓMEZ, 2008; MARTINEZ-CRESPO et al, 2009; GARCÍA, 2009; STEELE; DAWSON; HILLER, 2006; GENT et

\footnotetext{
"Curso de Fisioterapia. Programa de Pós-Graduação da Escola de Educação Física Universidade Federal do Rio Grande do Sul(UFRGS). Porto Alegre, RS, Brasil. E-mail: claudia.candott@ @ufrgs.br "Universidade do Vale do Rio dos Sinos. Novo Hamburgo, RS, Brasil. E-mail: joicerohr@yahoo.com.br

"'Programa de Pós-Graduação em Ciências do Movimento Humano. Escola de Educação Física. Universidade federal do Rio Grande do Sul (UFRGS). Porto Alegre, RS, Brasil. Email: matiasnoll@yahoo.com.br
} 
al, 2003; KELLIS; EMMANOUILIDOU, 2010). Exemplo disto, Shehab e Jarallah (2005), em estudo realizado com 440 escolares de 10 a 18 anos no Kuwait, verificaram percentuais elevados da prevalência de dor lombar e que estes aumentaram com o aumento da idade. Aos 10 anos $31 \%$ dos avaliados relataram dor lombar, em comparação com $74 \%$ dos avaliados de 18 anos de idade em ambos os sexos.

Da mesma forma, outros estudos, desenvolvidos no Brasil, demonstram resultados preocupantes. Santos et al (2009), avaliaram 247 escolares da $1^{\mathrm{a}}$ a $4^{\mathrm{a}}$ série do Ensino Fundamental e observaram que cerca de $20 \%$ das crianças apresentavam de três a quatro alterações posturais, sendo que apenas $2 \%$ dos escolares não apresentaram nenhuma alteração postural. Em outro estudo com escolares do Ensino Fundamental (CORREA; PEREIRA; SILVA, 2005), foi encontrado, nas meninas, um percentual maior de alterações posturais, cerca de $86 \%$, em comparação aos meninos (73\%). Entretanto, mesmo havendo esta diferença no percentual entre os sexos, ambos são extremamente elevados. No estudo realizado com 495 alunas de 14 a 18 anos na cidade de São Leopoldo, Rio Grande do Sul, (DETSCH et al, 2007), mesmo estado em que foi realizado o presente estudo, verificou-se uma prevalência de $66 \%$ para as alterações posturais laterais e de $70 \%$ para as alterações ânteroposteriores da coluna vertebral. $\mathrm{O}$ mesmo grupo de pesquisadores (DETSCH; CANDOTTI, 2001), em estudo similar realizado também no Rio Grande do Sul, avaliaram a incidência de desvios posturais em 154 escolares da cidade de Novo Hamburgo, de 6 a 17 anos, e observaram que $70,78 \%$ dos avaliados apresentaram alguma alteração postural na coluna vertebral.

Considerando a alta prevalência de dor lombar e alterações posturais encontrados na idade escolar, e visto que a educação postural está contemplada nos Parâmetros Curriculares de Educação Física (1997), sendo este um conteúdo obrigatório no ensino básico, assume-se ser relevante e necessária a implantação de programas de orientação e educação postural, e prevenção das alterações na postura corporal (DETSCH et al, 2007) no ensino básico. 
A educação postural, embora muito presente na fala de profissionais da saúde, tanto da Educação Física quanto da Fisioterapia, carece de maior entendimento sobre seu significado, fato este evidenciado na literatura. Pode-se dizer que a educação postural consiste em uma prática pedagógica baseada em experiências de aprendizagem que preconiza a aquisição de conceitos e comportamentos que podem modificar os hábitos posturais adquiridos ao longo da vida e o desenvolvimento da má postura (SOUZA; VIEIRA, 2003; REBOLHO; CASAROTTO; JOÃO, 2009; CANDOTTI et al, 2011). Neste sentido, a educação postural visa orientar sobre a importância de um adequado posicionamento do corpo e informar tanto sobre as consequiências da má postura, quanto sobre as maneiras adequadas de se realizar atividades do dia a dia, tais como: andar, sentar, dormir, utilizar computador, dirigir, etc. (VERDERI, 2005; CANDOTTI et al, 2009). Em outras palavras, a educação postural intervém sobre os hábitos posturais no sentido de promover mudanças positivas, ou seja, transformar maus hábitos em hábitos adequados de postura, prevenindo, possivelmente, dores e doenças musculoesqueléticas, sendo considerada uma ferramenta potencial para reduzir os efeitos da má postura sobre o organismo humano. Sendo assim, a educação postural pode ser entendida como um dos principais eixos na divulgação e orientação à população no que se refere à saúde e a qualidade de vida.

Vários pesquisadores têm demonstrado a importância do ensino de conhecimentos de anatomia e biomecânica, e hábitos posturais adequados nas atividades de vida diária (AVD's) na infância, visto que a postura adequada ou a correção precoce de desvios posturais nessa fase possibilitam padrões posturais adequados na vida adulta (MARTELLI; TRAEBERT, 2006; ZAPATER et al, 2004; CARDON et al, 2000). No entanto, não se tem conhecimento, até então, de estudos que investigaram e apresentem dados que demonstrem se o ensino de conhecimentos sobre postura corporal e hábitos adequados de postura durante a execução das AVD's é contemplado nos planos de estudos da disciplina de Educação Física em escolas do ensino básico. Deste modo, o presente trabalho visa 
investigar esta lacuna encontrada na literatura, tendo como objetivo verificar se a educação postural está contemplada nos conteúdos das aulas de Educação Física das escolas de Ensino Fundamental de $5^{\mathrm{a}}$ a $8^{\mathrm{a}}$ séries da Cidade de Montenegro/RS. Parte-se das seguintes premissas: (1) na visão dos professores, os conteúdos referentes à postura corporal são importantes de serem desenvolvidos nas aulas de Educação Física Escolar; (2) a educação postural não é integrante dos conteúdos das aulas de Educação Física Escolar; e (3) os professores não serão capazes de definir o termo "postura adequada".

\section{Metodologia}

Este estudo é de base populacional, pois participaram do estudo todos os professores de Educação Física de todas as escolas estaduais, públicas e privadas, totalizando 18 escolas, de $5^{\mathrm{a}}$ a $8^{\mathrm{a}}$ séries da rede de ensino da Cidade de Montenegro/RS. Todos os professores de Educação Física participaram voluntariamente da pesquisa, assim como assinaram um Termo de Consentimento Livre e Esclarecido.

\subsection{INSTRUMENTO DE COLETA}

Foi elaborado especificadamente para este estudo um questionário contendo 18 questões fechadas e uma questão aberta. $\mathrm{O}$ assunto abordado refere-se à Educação Física escolar, delimitandose a aprendizagem e vivências em educação postural. As perguntas realizadas são em relação à formação do profissional, atuação do professor na escola, metodologia de trabalho, conhecimentos gerais e específicos sobre postura e anatomia corporal, bem como a opinião dos professores em relação ao conceito de "postura adequada".

Este questionário foi submetido ao procedimento de validação de conteúdo ao ser analisado por três professores universitários especialistas na área de educação postural, todos com doutorado em Ciências do Movimento Humano. Os resultados deste procedimento de validação de conteúdo demonstraram que todos os três especialistas referiram que o instrumento é aplicável e específico 
para avaliar com precisão o que objetiva. Do mesmo modo foi realizado o procedimento de teste-reteste, para verificar a fidedignidade do instrumento. Para este procedimento de verificação da fidedignidade, o questionário foi respondido por 15 professores de Educação Física, não participantes do presente estudo, em dois momentos distintos, com intervalo de sete dias entre eles. As respostas obtidas nestes dois dias foram submetidas ao teste de Correlação de Spearman, o qual demonstrou forte e significativa correlação (r?0,9 e $\mathrm{p}<0,05)$ para todas as questões fechadas. Os resultados dos procedimentos de validação de conteúdo e de fidedignidade indicam que o questionário está elaborado com questões claras e objetivas, sendo considerado um instrumento válido e fidedigno (THOMAS; NELSON, 2002; GAYA, 2008).

\subsection{PROCEDIMENTOS DE COLETA E ANÁLISE DAS INFORMAÇÕES}

A coleta de informações ocorreu no período de março a junho de 2009. As dezoito escolas de $5^{\mathrm{a}}$ a $8^{\mathrm{a}}$ séries da Cidade de Montenegro/ RS foram visitadas, sendo que todas aceitaram participar do estudo, por meio da autorização dos diretores das instituições. Depois deste contato inicial, todos os professores de Educação Física destas escolas $(n=22)$ foram convidados a participar do estudo e receberam, em mãos, de um dos pesquisadores, o termo de consentimento livre e esclarecido, em duas vias, e o questionário. Foi estabelecido o prazo de uma semana para o retorno dos questionários, entregues na direção das escolas, sendo recolhidos pelos pesquisadores. Todos os 22 professores convidados devolveram o questionário respondido, juntamente com uma via do termo de consentimento livre e esclarecido.

Para análise do questionário, as respostas das 18 questões fechadas foram codificadas e tabuladas, sendo o tratamento estatístico realizado no software SPSS 18.0, através de estatística descritiva, utilizando tabelas de freqüências. Especificamente, foram submetidos ao teste qui-quadrado ( 2) os resultados (1) sobre a importância da educação postural para os alunos no ensino básico e (2) sobre os conhecimentos específicos referentes à coluna vertebral abordados 
nas aulas de Educação Física, visando verificar se existia diferença significativa entre as freqüências das respostas obtidas. Foi também calculada a média e o desvio-padrão da idade e do número de turmas de cada professor. O nível de significância adotado foi de 0,05 .

Para análise da questão 19 (questão aberta), referente ao conceito de "postura adequada", as respostas foram agrupadas em unidades temáticas, visando analisar com mais profundidade os significados dados pelos professores para o termo "postura adequada".

\section{Resultados}

Para melhor visualização e compreensão dos resultados, optouse por apresentá-los subdivididos em secções, tais como: caracterização da amostra, planejamento das aulas (metodologia de trabalho dos professores, importância dos conteúdos) e definição do termo postura corporal adequada.

\subsection{CaracterizaÇÃo da AMOStra}

Ao todo, 22 professores de Educação Física do ensino fundamental participaram do estudo, sendo $13,6 \%(n=3)$ do sexo masculino e $86,4 \%(n=19)$ do sexo feminino. A média de idade dos professores que participaram do estudo foi de 44,6 8,4 anos. Quanto à identificação das escolas participantes, 22,7\% $(\mathrm{n}=5)$ dos professores lecionavam na rede municipal, $63,6 \%(n=14)$ na rede estadual e $13,6 \%$ $(\mathrm{n}=3)$ na rede particular de ensino.

Quanto à carga horária de trabalho de cada professor no ensino de Educação Física Escolar, observou-se que 40,9\% (n=9) dos professores trabalhavam até 20 horas semanais e $59,1 \%(n=13)$ trabalhavam de 21 a 40 horas semanais. Quanto ao tempo de conclusão do curso de graduação, verificou-se que $68,2 \%(n=15)$ dos professores estavam formados há mais de 10 anos, 18,2\% $(\mathrm{n}=4)$ estavam formados de 4 a 9 anos e 13,6\% (n=3) de 1 a 3 anos. Referente ao tempo de atuação na escola em questão, $50 \%(\mathrm{n}=11)$ 
dos professores afirmaram já estar atuando a mais de 10 anos na escola, 27,3\% (n=6) de 1 a 3 anos, 13,6\% (n=3) de 4 a 9 anos e $9,1 \%(\mathrm{n}=2)$ há menos de 1 ano na escola.

Quanto aos professores terem ou não cursado uma disciplina de Educação Postural ou alguma disciplina semelhante no seu curso de graduação em Educação Física, os resultados evidenciaram que $50 \%(n=11)$ dos professores não cursaram nenhuma disciplina no seu curso de graduação que abordasse os conteúdos de Educação Postural (Tabela 1). Quando perguntado se os professores consideram importante ensinar e praticar a educação postural com os alunos no ensino básico, um número significativo de professores $(90,9 \% ; \mathrm{n}=20 ; 2=14,727 ; \mathrm{p}<0,001)$ responderam que sim, é importante ensinar educação postural.

Tabela 1 - Frequência sobre a realização de alguma disciplina sobre postura na graduação em Educação Física cursada pelos professores

\begin{tabular}{lcc}
\hline Disciplina de Educação Postural (EP) & Freqüência & Percentagem \\
\hline Sim, cursei disciplina de EP & 8 & 36,4 \\
Não cursei disciplina de EP & 11 & 50 \\
Não recordo & 1 & 4,5 \\
Cursei disciplina semelhante & 2 & 9,1 \\
\hline Total & 22 & 100 \\
\hline
\end{tabular}

\subsection{Planejamento das aUlas}

Os resultados referentes ao embasamento teórico para o planejamento das aulas de Educação Física demonstraram que apenas $27,3 \%(n=6)$ dos professores baseiam-se no plano anual de trabalho, em bibliografia da área e nos PCNS (Tabela 2). 
Tabela 2 - Frequência sobre o embasamento teórico para o planejamento das aulas de Educação Física

\begin{tabular}{lcc}
\hline Bases teóricas para planejamento das aulas & Freqüência & Percentagem \\
\hline Plano trabalho (PT) & 8 & 36,4 \\
Bibliografia (B) & 2 & 9,1 \\
Parâmetros Curriculares Nacionais (PCN), PT e B & 6 & 27,3 \\
PCN e PT & 5 & 22,7 \\
PCN e B & 1 & 4,5 \\
\hline Total & 22 & 100,0 \\
\hline
\end{tabular}

Fonte: Autores

Quanto aos assuntos abordados nas aulas de Educação Física, observou-se que 54,5\% $(n=12)$ dos professores afirmaram que desenvolvem em suas aulas atividades clássicas da Educação Física (esportes, jogos, lutas, ginásticas), atividades rítmicas e expressivas e conhecimentos sobre o corpo humano (Tabela 3). Referente aos conhecimentos sobre o corpo humano desenvolvidos nas aulas de Educação Física, um número significativo de professores ( $2=8$; $\mathrm{p}=0,005$ ) desenvolve estes conhecimentos sobre o corpo humano e coluna vertebral de forma geral, e apenas poucos professores trabalham os conhecimentos específicos sobre a coluna vertebral (Tabela 4).

Tabela 3 - Freqüência sobre os assuntos abordados nas aulas de Educação Física

\begin{tabular}{lcc}
\hline Assuntos Abordados & Freqüência & Percentagem \\
\hline Atividades clássicas & 4 & 18,2 \\
Atividades clássicas, rítmicas e conhecimento & 12 & 54,5 \\
Atividades clássicas, conhecimento & 4 & 18,2 \\
Atividades rítmicas, conhecimento & 2 & 9,1 \\
\hline Total & 22 & 100,0 \\
\hline
\end{tabular}

Fonte: Autores

Movimento, Porto Alegre, v. 17, n. 03, p. 57-77, jul/set de 2011. 
Tabela 4 - Freqüência sobre os conhecimentos específicos referentes à coluna vertebral abordados nas aulas de Educação Física

\begin{tabular}{lcc}
\hline Conhecimentos Gerais: Corpo Humano & Freqüência & Percentagem \\
\hline Conhecimentos específicos sobre coluna vertebral & 3 & 13,6 \\
Conhecimentos gerais sobre o corpo & 10 & 45,5 \\
Conhecimentos gerais sobre o corpo e coluna & 5 & 22,7 \\
vertebral & & \\
\hline Total & 18 & 81,8 \\
\hline Não responderam a questão & 4 & 18,2 \\
\hline Total & 22 & 100,0 \\
\hline
\end{tabular}

Fonte: Autores

Os dados referentes à capacidade do professor em lecionar o conteúdo de Educação Postural demonstraram que apenas 63,6\% $(n=14)$ sentem-se aptos a este tipo de trabalho e que $36,4 \%(n=8)$ referiram necessitar de uma atualização para desenvolver este tipo de conteúdo. Os dados referentes às respostas sobre os conteúdos que o tema Educação Postural deveria abordar estão demonstrados na Tabela 5. Dentre os principais conteúdos citados pelos professores estão: postura (adequada, inadequada e alterações posturais), consciência corporal e conhecimento teórico sobre coluna vertebral. Os dados referentes à faixa etária em que a Educação postural deveria ser iniciada, segundo os professores, estão demonstrados na Tabela 6.

Tabela 5 - Freqüência sobre os assuntos que devem ser abordados na Educação Postural

\begin{tabular}{lcc}
\hline Assuntos abordados na educação postural & Freqüência & Percentagem \\
\hline Postura, consciência corporal, conhecimento & 16 & 72,7 \\
Postura & 1 & 4,5 \\
Postura e consciência corporal & 5 & 22,7 \\
\hline Total & 22 & 100,0 \\
\hline
\end{tabular}

Fonte: Autores

Movimento, Porto Alegre, v. 17, n. 03, p. 57-77, jul/set de 2011. 
Tabela 6 - Freqüência sobre a idade em que a Educação postural deveria ser iniciada

\begin{tabular}{llc}
\hline $\begin{array}{l}\text { Idade de início da educação postural nos } \\
\text { indivíduos }\end{array}$ & Freqüência & Percentagem \\
\hline A partir 1 ano de idade & 11 & 50,0 \\
A partir 5 anos de idade & 8 & 36,4 \\
A partir 10 anos de idade & 3 & 13,6 \\
\hline Total & 22 & 100,0 \\
\hline
\end{tabular}

Fonte: Autores

\subsection{DefinIÇÃO DE "POSTURA ADEQUADA"}

Os professores responderam a questão aberta e descritiva, referente ao conceito de "postura adequada", conforme sua opinião. A partir das respostas de todos os professores, foi realizada inicialmente uma análise geral das respostas e, em um segundo momento estas respostas foram agrupadas em quatro unidades temáticas: 1) Bem-Estar/Boa forma; 2) Respeite dos limites corporais; 3) Consciência corporal; e 4) Equilíbrio corporal. No texto a seguir, são descritas cada uma destas temáticas, juntamente com a definição de alguns professores, na tentativa de melhor compreender os significados dados pelos mesmos.

Na unidade temática Bem Estar/Boa forma foram incluídas as visões de treze professores sobre o termo "postura adequada". Segundo os professores, "postura adequada" corresponde ao estado de saúde, vitalidade e ausência de dor em que o corpo do indivíduo está ou deveria estar. Esta visão é bem ilustrada na fala da professora "A", que define "postura adequada" como:

[...] corpo saudável, com atividade física moderada e sentir-se bem, sem dores na coluna ou articulações. Uma boa postura nos faz sentir melhor. Em minha opinião deveríamos ter um posturógrafo em todas as escolas, para desde cedo prevenir e corrigir a postura de todos os alunos.

Na segunda unidade temática, Respeito dos Limites Corporais, a visão de sete professores foram incluídos e, segundo os professores, "postura adequada" inclui respeitar a individualidade biológica de cada 
ser humano, compreendendo que nas tarefas diárias e no trabalho não se pode realizar ações que o corpo não tenha condições e forças necessárias de executar. A professora "B" escreveu o seguinte trecho a esse respeito:

[...] quando os alunos respeitam os limites do próprio corpo e utilizam a postura adequadamente para que isso não interfira no seu crescimento e de conseqüências futuras.

Na terceira unidade temática, Consciência Corporal, onze professores foram incluídos. Segundo estes professores, "postura adequada" é o discernimento de que para se ter uma postura adequada, é preciso compreender como o corpo humano reage e se expressa em diferentes situações. Nesse sentido, ilustra-se a fala da professora "C", a qual abrange o conceito de "postura adequada" em vários aspectos, tais como:

[...] como somos biologicamente diferentes varia de uma pessoa para a outra. A melhor postura que deve ser adotada por uma pessoa é aquela que preenche todas as necessidades mecânicas do corpo e também que possibilita ao indivíduo manter uma posição ereta com o mínimo de esforço muscular. A boa postura na realização das Atividades da Vida Diária - AVD's é o principal fator para se evitar os desequilíbrios posturais. A maneira de se posicionar e a conscientização corporal são muito importantes, pois sem esses cuidados pode-se desencadear todo o processo de desequilíbrios posturais e das síndromes dolorosas posturais.

E, por fim, na última unidade temática, Equilíbrio Corporal, cinco professores foram incluídos. Segundo a professora "D" e a professora "E" o conceito de "postura adequada" está diretamente relacionado com o equilíbrio corporal, e isto pode ser constatado a partir das suas respostas:

A boa postura envolve o conceito de equilíbrio, coordenação neuromuscular e adaptação, e deve ser aplicado a um determinado momento corporal e para uma determinada circunstância da vida do 
indivíduo, como exemplos: postura para andar, jogar, realizar movimentos variados. Posturas ou movimentos inadequados produzem tensões mecânicas nos músculos, ligamentos e articulações resultando em dores no sistema músculo-esquelético. (Professora D)

Na minha opinião uma boa postura é um estado de equilíbrio entre músculos e ossos, com a capacidade de proteger as outras estruturas do nosso corpo. (Professora E)

Como pode ser observado nas questões levantadas pelos professores, o termo "postura adequada" tem sido relacionado ao fato do indivíduo se sentir bem, estar em forma, respeitar e ter consciência do seu corpo além de um equilíbrio corporal adequado.

\subsection{DısCUSSÃO}

O objetivo geral deste estudo foi verificar se a educação postural está sendo contemplada nos conteúdos das aulas de Educação Física das escolas de Ensino Fundamental de $5^{\mathrm{a}}$ a $8^{\mathrm{a}}$ séries da Cidade de Montenegro/RS. Os principais resultados encontrados demonstraram que $90,9 \%(n=20)$ dos professores consideram importante ensinar e praticar a educação postural com os alunos, mas apenas 13,6\% $(n=3)$ trabalham este conteúdo específico em suas aulas. Estes resultados sugerem que, mesmo a Educação Postural sendo considerada importante, é negligenciada nas aulas de Educação Física pela maioria dos professores, independente da rede de ensino, tanto nos aspectos do conhecimento teórico, nas AVD's e durante as práticas vivenciadas, confirmando as duas premissas iniciais do estudo de que: (1) na visão dos professores, os conteúdos referentes à postura corporal seriam importantes nas aulas de Educação Física Escolar e (2) a educação postural não seria integrante dos conteúdos das aulas de Educação Física Escolar. Do mesmo modo, outros pesquisadores (REBOLHO; CASAROTTO; AMADO, 2009; MARTELLI; TRAEBERT, 2006) também referem que não há ênfase nos aspectos preventivos referentes à postura no ensino básico e nos sistemas de saúde. 
Quanto à base teórica para planejamento das aulas de EFI dos professores de $5^{\mathrm{a}}$ a $8^{\mathrm{a}}$ séries da Cidade de Montenegro/RS, os resultados demonstraram que apenas $27,3 \%(n=6)$ dos professores baseiam-se no plano anual de trabalho, em bibliografia da área e nos PCNs. Estes resultados indicam que a maioria dos professores não prioriza os três meios ou possibilidades de embasamento teórico para o planejamento de suas aulas.

Nos PCNs (2000) os conteúdos estão organizados em três blocos, sendo que o bloco "Conhecimentos sobre o corpo" aborda conhecimentos anatômicos, fisiológicos, biomecânicos e bioquímicos, assim como também fazem parte desse bloco os conhecimentos sobre os hábitos posturais e atitudes corporais. Considerando que doze professores consultam os PCNs anualmente, mas apenas três trabalham a educação postural com seus alunos, percebe-se que os hábitos saudáveis e o desenvolvimento corporal sadio dos educandos não parecem ser uma preocupação primordial destes professores.

Os resultados referentes aos assuntos abordados nas aulas de Educação Física, pelos professores de $5^{\mathrm{a}}$ a $8^{\mathrm{a}}$ séries da Cidade de Montenegro/RS, demonstraram que 54,5\% $(n=12)$ dos profissionais afirmam que abordam esportes, jogos, lutas, ginásticas, atividades rítmicas e expressivas e conhecimentos sobre o corpo humano. Os achados do presente estudo estão de acordo com os encontrados por Molina (1998), o qual demonstrou que os professores de educação física geralmente programam os conteúdos de suas aulas seguindo basicamente três orientações gerais para cada nível de ensino: atividades globalizadas até a $4^{\mathrm{a}}$ série do ensino fundamental, aprendizagem desportiva de $5^{\mathrm{a}}$ a $8^{\mathrm{a}}$ série do mesmo nível de ensino, e prática desportiva para o ensino médio. Entretanto, no presente estudo, não fica claro de que forma os professores abordam todas essas questões nem a freqüência de desenvolvimento dos assuntos, e, em especial o conhecimento sobre o corpo. Considera-se esta uma limitação do presente estudo, ou seja, a lacuna sobre dados concretos da maneira como os professores contemplam os temas em aula. 
Quanto a sentirem-se aptos em desenvolver a educação postural em suas aulas, apenas 63,6\% dos professores se sentem aptos em trabalhar este conteúdo. Pode-se notar uma oposição entre uma questão e outra. Se 90,6\% consideram relevante ensinar e praticar questões sobre educação postural com alunos de $5^{\mathrm{a}}$ a $8^{\mathrm{a}}$ séries, questiona-se: por que apenas $63,6 \%$ se sentem aptos e apenas $13,6 \%$ dos professores desenvolvem-na com seus alunos? Considerando que os resultados do presente estudo evidenciaram que os professores sabem da importância do conteúdo "postura corporal", entende-se que os mesmos, com o apoio da escola poderiam se mobilizar e trabalhar as questões do corpo com seus alunos e inclusive, estender esses benefícios à comunidade escolar e aos familiares (RITTER; SOUZA, 2006).

Quanto ao fato dos professores terem obtido seus conhecimentos sobre postura no seu curso de graduação, os resultados demonstraram que 45,4\% (n=10) dos professores não cursaram nenhuma disciplina no seu curso de graduação que abordasse os conteúdos de Educação Postural. Não obstante, este fato não justifica a não inclusão deste conteúdo nos planos de aula, visto que os escolares têm direito a este aprendizado, pois a falta de informações, por exemplo, da postura adequada durante as atividades escolares e AVD's, pode ser um fator de risco para a integridade da coluna vertebral, facilitando sua exposição a sobrecargas inadequadas, que a médio e longo prazo, podem gerar o achatamento das vértebras, desgastes nas articulações e, conseqüentemente dores e problemas de coluna vertebral (VIEIRA; SOUZA, 1999). Conforme Detsch et al (2007) a maioria dos problemas posturais, especialmente aqueles relacionados com a coluna vertebral, tem sua origem no período de crescimento e desenvolvimento corporal, ou seja, na infância e na adolescência. Deste modo, entende-se que mesmo aqueles professores que não cursaram nenhuma disciplina no seu curso de graduação que abordasse os conteúdos de Educação Postural deveriam atualizarse, visando a inclusão deste conteúdo dentre os desenvolvidos ao longo do ano letivo. 
Os achados do presente estudo, referentes à idade em que a educação postural deve ser iniciada, surpreendem, pois onze professores acreditam que ela deve ser iniciada antes do ensino fundamental (a partir de um ano de idade), o que se contrapõe com o desenvolvimento motor e cognitivo da criança. Gallahue e Ozmun (2005) destacam que de zero aos seis anos de idade a criança está em plena fase de desenvolvimento motor, sendo que seria muito complexo e até incoerente trabalhar a educação postural nesse período. Portanto, percebe-se um equívoco da parte dos professores demonstrando a fragilidade do conhecimento dos mesmos sobre o assunto, ou seja, sobre o desenvolvimento motor e cognitivo e sobre a complexidade do tema postura para a faixa etária anterior ao ensino fundamental. Neste sentido, para Black (1993) e Candotti et al (2009), o ensino da educação postural deve começar no ensino fundamental, por meio de conteúdos teóricos e práticos sobre a coluna vertebral e postura adequada nas AVD's. A escola deve ser vista como o local ideal para os primeiros contatos da criança com os primeiros conceitos de educação postural (CARDON et al, 2000). Além disto, é na escola que se encontra o maior número de crianças reunidas, o que facilita o desenvolvimento de programas de Educação Postural, ou seja, programas que visem informá-las sobre a importância de melhores posicionamentos de postura no intuito de prevenir os desequilíbrios posturais. Assim são justificadas todas as formas de intervenção precoce, desde que na faixa etária adequada de desenvolvimento, pois a postura adequada na infância e/ou a correção de desvios posturais nessa fase, possibilitam padrões posturais adequados na vida adulta (BAKKER et al, 2009; VIEIRA; SOUZA, 1999; SOUZA, 1996).

Partindo deste pressuposto entende-se que os professores de Educação Física podem balizar o planejamento de suas aulas amparados por vários estudos disponíveis na literatura nacional. Por exemplo, Candotti et al (2009), depois de avaliarem a postura estática, a postura dinâmica e o conhecimento teórico sobre postura de 28 crianças entre 8 e 11 anos de idade, de ambos os sexos, desenvolveram um programa de Educação Postural para estas crianças. Seus resultados demonstraram que os participantes do 
programa de Educação Postural aprenderam a conhecer e a identificar a coluna vertebral, suas partes e funções, e a manter as suas curvaturas durante as AVD's. Além deste, outros estudos podem ser consultados pelos professores referentes ao ensino da educação postural (BLACK, 1993; REBOLHO; CASAROTTO; AMADO, 2009; RITTER; SOUZA, 2006; SOUZA, 1996; VERDERI, 2005; VIEIRA; SOUZA, 1999; ZAPATER et al, 2004).

Os achados do presente estudo, referentes à definição do termo "postura adequada", demonstraram que os professores o definem de forma adequada, possivelmente a partir das suas experiências de vida, embora não consigam aplicá-lo na sua prática profissional. Em linhas gerais, as unidades temáticas Bem-Estar/Boa Forma, Respeito dos limites corporais, Consciência corporal e Equilíbrio corporal sintetizam as respostas dos professores na definição de "postura adequada", as quais se apresentam muito similares às definições encontradas na literatura atual da área (VERDERI, 2005; SANTOS et al, 2009; KARAHAN; BAYRAKTAR, 2004; HARRISON et al, 1999; VICKERY: MOFFAT, 2002; VIEIRA; SOUZA, 1999). Estes resultados foram considerados surpreendentes ao mostraremse contrários a terceira premissa do estudo, a qual preconizava que os professores não seriam capazes de definir, em acordo com a literatura, o termo "postura adequada".

Cardon et al (2000) destacam que ao iniciar-se a prevenção já nos primeiros anos do Ensino Fundamental, a possibilidade de serem realizados reforços de aprendizagem é prolongada, e grande porcentagem da população pode ser educada. Desta forma os jovens podem aprender a estabelecer padrões adequados de movimento sem ter que quebrar padrões ineficientes e hábitos inadequados (REBOLHO; CASAROTTO; AMADO, 2009; CARDON et al, 2000). Em suma, as ações de caráter preventivo são as mais fáceis, mais rápidas, e de melhor prognóstico (DELOROSO, 1999; SOUZA, 1996). Portanto, iniciativas que visem educar a postura durante essas atividades são medidas que deveriam ser pensadas pela comunidade escolar. 


\section{ConclusÃo}

Os resultados demonstraram que os conteúdos da temática "Educação Postural" não integram as aulas de Educação Física das escolas de $5^{\mathrm{a}}$ a $8^{\mathrm{a}}$ séries da Cidade de Montenegro/RS, sendo significativamente negligenciados pela maioria dos professores. Não obstante, houve um reconhecimento significativo por parte dos professores sobre a importância de ensinar e praticar questões acerca da "Educação Postural". Além disto, os resultados também demonstraram que os professores foram capazes de definir de forma similar à literatura o conceito do termo "postura adequada", o que sugere uma notável contradição entre pensar e fazer. 
Postural Education as Curriculum Content of Physical Education in Elementary Education Schools in The City of Montenegro / RS

Abstract: This study aimed to verify if the Postural Education is included in the contents of physical education classes in schools from elementary school for 5th to 8th grades in the city of Montenegro/RS. Twenty-two teachers responded to a selfadministered questionnaire. The results showed that the Education Posture, in practice, is neglected by most physical education teachers from 5th to 8th grades, but teachers recognize the importance of teaching and practice issues on Education Postural and define very well the concept of posture adequate, which suggests a remarkable contradiction between thinking and doing.

Keywords: Posture. Schools. Physical Education

Educación Postural como Contenido Curricular de la Educación Física en Educación Primaria Escuelas en la Ciudad de Montenegro / RS

Resumen: Este estudio tuvo como objetivo verificar si la educación postural está incluido en el contenido de las clases de educación física en las escuelas primaria de quinto a octavo grados en la ciudad de Montenegro/RS. Veintidós profesores respondieron a un cuestionario auto-administrado. Los resultados mostraron que la postura de Educación, en la práctica, es descuidado por la mayoría de profesores de educación física de quinto a octavo grados, pero los maestros reconocen la importancia de las cuestiones de la enseñanza y la práctica sobre la educación postural y definir muy bien el concepto de la postura adecuada, lo que sugiere una contradicción notable entre el pensamiento y el hacer

Palabras clave: Postura. Instituciones Académicas. Educación Física. 


\section{REFERÊNCIAS}

BAKKER, Eric et al. Spinal Mechanical Load as a risk factor for low back pain. Spine, Philadelphia, v. 34, n. 8, p. 281-93, 2009.

BLACK, Arno. Escola Postural: uma alternativa para a saúde da coluna vertebral. Porto Alegre: Ríegel, 1993.

CANDOTTI, Cláudia Tarragô et al. Efeitos de um programa de educação postural para crianças e adolescentes após oito meses do seu término. Revista Paulista de Pediatria. No prelo. 2011.

. Escola postural: uma metodologia adaptada para crianças. Arquivos em Movimento, Rio de Janeiro, v. 5, n. 2, p. 34-49, 2009.

CARDON, Greet et al. Effects of back care education in elementary schoolchildren. Acta Paediatric, Philadelphia, v. 89, p. 1010-7, 2000.

CORREA, Ana Lúcia; PEREIRA, João dos Santos; SILVA, Marco Antônio. Avaliação dos desvios posturais em escolares: estudo preliminar. Fisioterapia Brasil, Rio de Janeiro, v. 6, n. 3, p. 175-8, 2005.

DELOROSO, Frederico Tadeu. O estudo da postura corporal em Educação Física. 1999. Dissertação (Mestrado) - Faculdade de Educação Física, Universidade Estadual de Campinas. Campinas, SP, 1999.

DETSCH, Cíntia et al. Prevalência de alterações posturais em escolares do ensino médio em uma cidade no Sul do Brasil. Revista Panamericana de Salud Publica, Washington, v. 21, n. 4, p. 231-238, 2007.

DETSCH, Cíntia; CANDOTTI, Cláudia Tarragô. A incidência de desvios posturais em meninas de 6 a 17 anos da cidade de Novo Hamburgo. Revista Movimento, Porto Alegre, v. 7, n. 15, p. 43-56, 2001.

GALLAHUE, David; OZMUN, John. Compreendendo o desenvolvimento motor: bebês, crianças, adolescentes e adultos. São Paulo: Phorte, 2005.

GARCíA, Fraile. Dolor de espalda em alumnos de primaria y sus causas. Fisioterapia, Espanha, v. 31, n. 4, p. 137-42, 2009.

GAYA, Adroaldo. Ciências do movimento humano: introdução à metodologia de pesquisa. Porto Alegre: Artmed, 2008.

GENT, Charlotte et al. The Weight of Schoolbags and the Occurrence of Neck, Shoulder, and Back Pain in Young Adolescents. Spine, Philadelphia, v. 28, n. 9, p. 916-921, 2003. 
HARRISON, Donald et al. Sitting Biomechanics Part I: Review of the literature. Journal of Manipulative and Physiological Therapeutics, Philadelphia, v. 22, n. 9, p. 594-609, 1999.

KARAHAN, Azize; BAYRAKTAR, Na. Determination of the usage of body mechanics in clinical settings and the occurrence of low back pain in nurses. International Journal of Nursing Studies, Londres, v. 41, p. 67-75, 2004.

KELLIS, Eleftherios; EMMANOUILIDOU, Maria. The effects of age and gender on the weight and use of schoolbags. Pediatric Physical Therapy, Philadelphia, v.22, p.17-45, 2010.

MARTELLI, Raquel Cristina; TRAEBERT, Jéferson. Estudo descritivo das alterações posturais de coluna vertebral em escolares de 10 a 16 anos de idade. Revista Brasileira de Epidemiologia, São Paulo, v. 9, n. 1, p. 87-93, 2006.

MARTINEZ-CRESPO, Garcia et al. Dolor de espalda em adolescentes: prevalência y fatores associados. Rehabilitacion, Madri, v. 43, n. 2, p. 72-80, 2009.

MOLINA NETO, Vicente. A prática dos professores de educação física das escolas públicas de Porto Alegre. Revista Movimento, Porto Alegre, v. 5, n. 9, p. 31-46, 1998.

REBOLHO, Maria Christina; CASAROTTO, Raquel Aparecida; AMADO, Silvia Maria. Estratégias para ensino de hábitos posturais em crianças: história em quadrinhos versus experiência prática. Fisioterapia e Pesquisa, São Paulo, v. 16, n. 1, p. 46-51, 2009.

RIBEIRO, Cardoso; GÓMEZ, Conesa. Lower back pain: prevalence and preventive programs in childhood and adolescence. Revista Iberoamericana Fisioterapia e Kinesiologia, Espanha, v. 11, n. 1, p. 32-38, 2008.

RITTER, Alexandre; SOUZA, Jorge Luiz. Instrumento para conhecimento da percepção de alunos sobre a postura adotada no ambiente escolar - POSPER. Revista Movimento, Porto Alegre, v. 12, n. 3, p. 249-62, 2006.

SANTOS, Camila Isabel et al. Ocorrência de desvios posturais em escolares do ensino público fundamental de Jaguariúna, São Paulo. Revista Paulista de Pediatria, São Paulo, v.27, n.1, p.74-80, 2009.

SHEHAB, Dia; JARALLAH, Khaled; Nonspecific low-back pain in Kuwaiti children and adolescents: associated factores. Journal of adolescent Health, Califórnia, v. 36, p. 32-35, 2005.

SOUZA, Jorge Luiz. Efeitos de uma Escola Postural para indivíduos com dores nas costas. Revista Movimento, Porto Alegre, v. 2, n. 5, p. 56-71, 1996.

SOUZA, Jorge Luiz; VIEIRA, Adriane. Escola postural: um caminho para o conhecimento de si e o bem-estar corporal. Revista Movimento, Porto Alegre, v. 9, p. 101-22, 2003. 
STEELE, Emily; DAWSON, Anna; HILLER, Janet. School-Based interventions for spinal Pain. Spine, Philadelphia, v. 31, n. 2, p. 226-33, 2006.

THOMAS, Jerry; NELSON, Jack. Métodos de pesquisa em atividade física. Porto Alegre: Artmed, 2002.

VERDERI, Erica. Programa de educação postural. São Paulo: Phorte, 2005.

VICKERY, Steve; MOFFAT, Mailyn. Manual de manutenção e reeducação postural. Porto Alegre: Artmed, 2002.

VIEIRA, Adriane; SOUZA, Jorge Luiz. Verticalidade é sinônimo de boa postura? Revista Movimento, Porto Alegre, v. 5, n. 10, p. 1-8, 1999.

ZAPATER, André Rocha et al. Postura sentada: a eficácia de um programa de educação para escolares. Ciência \& Saúde Coletiva, Rio de Janeiro, v. 9, n. 1, p. 191-199, 2004.

Endereço para correspondência:

Cláudia Tarragô Candotti

Rua Felizardo 750

Bairro Jardim Botânico

Porto Alegre, RS

CEP 90610-200

Recebido em: 24.01.2011

Aprovado em: 20.07.2011 
